\title{
Clinical significance of HSP27 expression in colorectal cancer
}

\author{
ZHIJIN YU ${ }^{1 *}, J_{U N L I} \mathrm{ZHI}^{3 *}$, XIAOFENG PENG ${ }^{2}$, XUHUI ZHONG ${ }^{1}$ and ANGAO XU ${ }^{1}$ \\ Departments of ${ }^{1}$ Gastroenterology, and ${ }^{2}$ Pathology, Huizhou Municipal Central Hospital, Huizhou; \\ ${ }^{3}$ College of Clinical Medicine, Guandong Pharmaceutical University, Guangzhou, Guangdong, P.R. China
}

Received June 15, 2010; Accepted September 16, 2010

DOI: $10.3892 / \mathrm{mmr} .2010 .372$

\begin{abstract}
The heat shock protein 27-kDa (HSP27) has been found overexpressed in several types of human cancer and is associated with treatment resistance and poor prognosis. Recent proteomic studies demonstrate that HSP27 is significantly overexpressed in colorectal cancer (CRC). However, the relationship between HSP27 expression and patient prognosis remains nascent. In the present study, we aimed to investigate the expression of HSP27 and its correlation with clinicopathological parameters in CRC patients. Dysregulated expression of HSP27 was observed in neoplastic lesions, and appears to be involved in disease progression. Immunohistochemical analysis showed that detectable HSP27 expression was found in 145/182 (79.7\%) CRC cases. There was a significant correlation between HSP27 expression and TNM stage $(\mathrm{P}=0.003)$. Patients with low HSP27 expression had better survival than those with high HSP27 expression. Additionally, multivariate analysis indicated that HSP27 expression is an independent prognostic marker for CRC. These results suggest that elevated expression of HSP27 protein is a frequent event during the progression of CRC. HSP27 might be used as a valuable prognostic marker for patients with CRC.
\end{abstract}

\section{Introduction}

Colorectal cancer (CRC) is one of the leading causes of malignancy-related deaths worldwide (1). The prognosis of CRC patients remains poor, with a 5-year survival rate of $\sim 45 \%$ reported in most studies, despite significant improvements in early diagnosis, surgery, chemotherapy and radiotherapy (2). Although TNM (tumor-node-metastasis) stage has been accepted as the most significant and independent prognostic factor, there are still many patients at the same stage who have different clinical outcomes (3). Therefore, the investigation and

Correspondence to: Dr Angao Xu, Department of Gastroenterology, Huizhou Municipal Central Hospital, No. 41 Eling Road, Huicheng District, Huizhou City, P.R. China

E-mail:mrangao@gmail.com

${ }^{*}$ Contributed equally

Key words: HSP27, colorectal cancer, prognosis application of molecular markers responsible for the development and progression of CRC are of utmost importance.

Heat shock proteins (HSPs) are detectable in virtually all organisms, from prokaryotes to mammals, and play a fundamental role in the maintenance of cellular homeostasis (4). Under physiological conditions, HSPs are constitutively expressed at a low level and function as molecular chaperones that fulfill important roles for protein folding, cellular signaling and protein degradation (5). HSPs have a stimulated synthesis in response to a variety of stressful stimuli (e.g., heat, heavy metal, infection or inflammation) and promote the refolding of damaged proteins (6). HSPs are classified by their molecular weight; the main HSP families comprise HSP110, HSP90, HSP70, HSP60 and the small HSPs (7).

HSP27, a small HSP, is ubiquitously expressed at low levels in normal cells (8). In contrast, its aberrant expression has been reported in a variety of human cancers, including breast (9), ovarian (10), gastric (11), prostate (12), endometrial (13), liver (14), bladder (15) and leukemia (16). Furthermore, elevated HSP27 levels in breast, ovarian, gastric, and prostate cancer is associated with aggressive growth and resistance to chemotherapy or radiotherapy, and hence with a poor prognosis (9-12). There is considerable evidence indicating that elevated expression of HSP27 in tumor cells enhances their tumorigenicity (17). In addition, HSP27 has been implicated in chemoresistance and the regulation of apoptosis (18). These data underscore the important role of HSP27 in the development and progression of malignancy. Recently, Liu and coworkers (19) found that HSP27 is aberrantly expressed in human $\mathrm{CRC}$ by performing a comparative proteomic study between CRC tissues and corresponding adjacent noncancerous colorectal tissues. However, there have been no reports concerning the expression level of HSP27 in human colorectal cancer samples associated with the clinical prognosis and progression of patients.

In this study, we used an immunohistochemical assay to evaluate the level of HSP27 expression in CRC. We then analyzed whether its expression levels were correlated with the main clinicopathologic variables and prognosis of CRC patients, in order to demonstrate its potential prognostic and/ or therapeutic implications for CRC.

\section{Materials and methods}

Patients and specimens. Paraffin-embedded archived CRC tissue blocks were obtained with the approval of the regional 
research ethics committee from 182 patients diagnosed with CRC between January 2004 and December 2005 at the Huizhou Center Hospital. Tissue sections were reviewed by a pathologist to confirm the diagnosis and accuracy of the existing data. The clinicopathological characteristics of the patients and their tumors are summarized in Table I. Complete follow-up was available for all patients and ranged from 1 to 60 months.

Western blotting. Protein extracts were ground in liquid nitrogen and lysed in RIPA lysis buffer $(50 \mathrm{mM}$ Tris- $\mathrm{HCl}$, $\mathrm{pH} 7.4,1 \% \mathrm{NP}-40,40 \mathrm{mM} \mathrm{NaF}, 10 \mathrm{mM} \mathrm{NaCl}, 10 \mathrm{mM} \mathrm{Na}_{3} \mathrm{VO}_{4}$, $1 \mathrm{mM}$ phenylmethylsulfonyl fluoride, $10 \mathrm{mM}$ dithiothreitol and $1 \mathrm{mg} / \mathrm{ml}$ each of leupeptin and aprotinin). Equal amounts of protein were subjected to $12 \%$ sodium dodecyl sulfate polyacrylamide gel electrophoresis (SDS-PAGE) and transferred to polyvinylidene difluoride (PVDF) membranes. After blocking with $5 \%$ nonfat milk in phosphate-buffered saline (PBS) containing $0.1 \%$ Tween-20 for $1 \mathrm{~h}$, the membranes were incubated at $4^{\circ} \mathrm{C}$ overnight with the primary antibody (HSP27 mouse mAb; Cell Signaling, Beverly, MA, USA). After incubation with a secondary antibody, the blots were visualized by enhanced chemiluminescence reagents (Thermo Scientific, Rockford, IL, USA).

Immunohistochemistry. The avidin-biotin complex method was used to detect the HSP27 protein. Formalin-fixed and paraffin-embedded tissues were deparaffinized with xylene and rehydrated in ethanol. After quenching of endogenous peroxidase activity with $3 \%$ hydrogen peroxide for $30 \mathrm{~min}$, the slides were submerged in EDTA antigenic retrieval buffer ( $\mathrm{pH}$ 8.0) and heated in a microwave oven. Sections were blocked for $30 \mathrm{~min}$ at $37^{\circ} \mathrm{C}$ with $1 \%$ bovine serum albumin (BSA). The primary antibody (HSP27 mouse mAb) was diluted with $1 \%$ BSA to $1: 100$ and incubated on slides in a moist chamber overnight at $4^{\circ} \mathrm{C}$. Biotinylated goat anti-mouse secondary antibody was applied for $15 \mathrm{~min}$ at $37^{\circ} \mathrm{C}$, followed by incubation with a complex of avidin with horseradish peroxidase for $15 \mathrm{~min}$ at $37^{\circ} \mathrm{C}$. Sections were developed with diaminobenzidine and counterstained with hematoxylin. Finally, the slides were sequentially dehydrated in ethanol and mounted. The negative control was stained by replacing the primary antibody with non-immune isotonic antibody. Assessment of immunostaining was performed by two independent observers who had no knowledge of the clinicopathologic variables. The level of HSP27 staining in the tumors was classified into four groups ( 0 , absent; 1 , weak; 2 , intermediate; 3 , strong staining) based on a scoring method described previously (20).

Statistical analysis. All statistical analyses were carried out using the SPSS package (version 13.0 for Windows, SPSS Inc.). The correlation between HSP27 expression and the clinicopathologic characteristics was determined by the $\chi^{2}$ test. The Spearman rank correlation was used to assess relationships between various variables. Survival curves were obtained by the Kaplan-Meier method. Differences in survival time between two groups were analyzed using the log-rank test. Multivariate analysis using the Cox proportional-hazards regression model was used to identify the independent effect
Table I. Clinicopathologic characteristics of the patients.

\begin{tabular}{|c|c|c|}
\hline & No. & $(\%)$ \\
\hline \multicolumn{3}{|l|}{ Gender } \\
\hline Male & 105 & 57.7 \\
\hline Female & 77 & 42.3 \\
\hline Age (years), mean (range) & $61(20-87)$ & \\
\hline$\leq 61$ & 86 & 47.3 \\
\hline$>61$ & 96 & 52.7 \\
\hline \multicolumn{3}{|l|}{ Status } \\
\hline \multicolumn{3}{|l|}{ Deceased } \\
\hline \multicolumn{3}{|l|}{ Alive } \\
\hline \multicolumn{3}{|l|}{ TNM stage } \\
\hline 0 & 6 & 3.3 \\
\hline $\mathrm{I}$ & 23 & 12.6 \\
\hline II & 88 & 48.4 \\
\hline III & 22 & 12.1 \\
\hline IV & 29 & 15.9 \\
\hline Unknown & 14 & 7.7 \\
\hline \multicolumn{3}{|l|}{ Tumor differentiation } \\
\hline Well & 93 & 51.1 \\
\hline Moderate & 52 & 28.6 \\
\hline Poor & 15 & 8.2 \\
\hline Unknown & 22 & 12.1 \\
\hline \multicolumn{3}{|l|}{ Tumor site } \\
\hline Colon & 54 & 29.7 \\
\hline Rectum & 128 & 70.3 \\
\hline \multicolumn{3}{|l|}{ Tumor size } \\
\hline$\leq 5 \mathrm{~cm}$ & 64 & 35.2 \\
\hline$>5 \mathrm{~cm}$ & 61 & 33.5 \\
\hline Unknown & 57 & 31.3 \\
\hline \multicolumn{3}{|l|}{ Chemotherapy after surgery } \\
\hline Yes & 69 & 37.9 \\
\hline No & 113 & 62.1 \\
\hline
\end{tabular}

of each variable in the cohort. A two-sided $\mathrm{P}<0.05$ was considered to be significant.

\section{Results}

Expression of HSP27 in paired CRC and adjacent noncancerous tissues. To investigate the expression level of HSP27 protein in CRC specimens, Western blot analysis was performed in four paired CRC samples (T) and adjacent noncancerous mucosa tissues $(\mathrm{N})$ from the same patient. The CRC samples showed significantly high levels of HSP27 expression compared with the adjacent non-cancerous mucosa tissues in all 4 examined samples (Fig. 1A). The differential overexpression was further confirmed by immunohistochemical analysis (Fig. 1B). These data suggest that the level of HSP27 protein expression was elevated in CRC. 

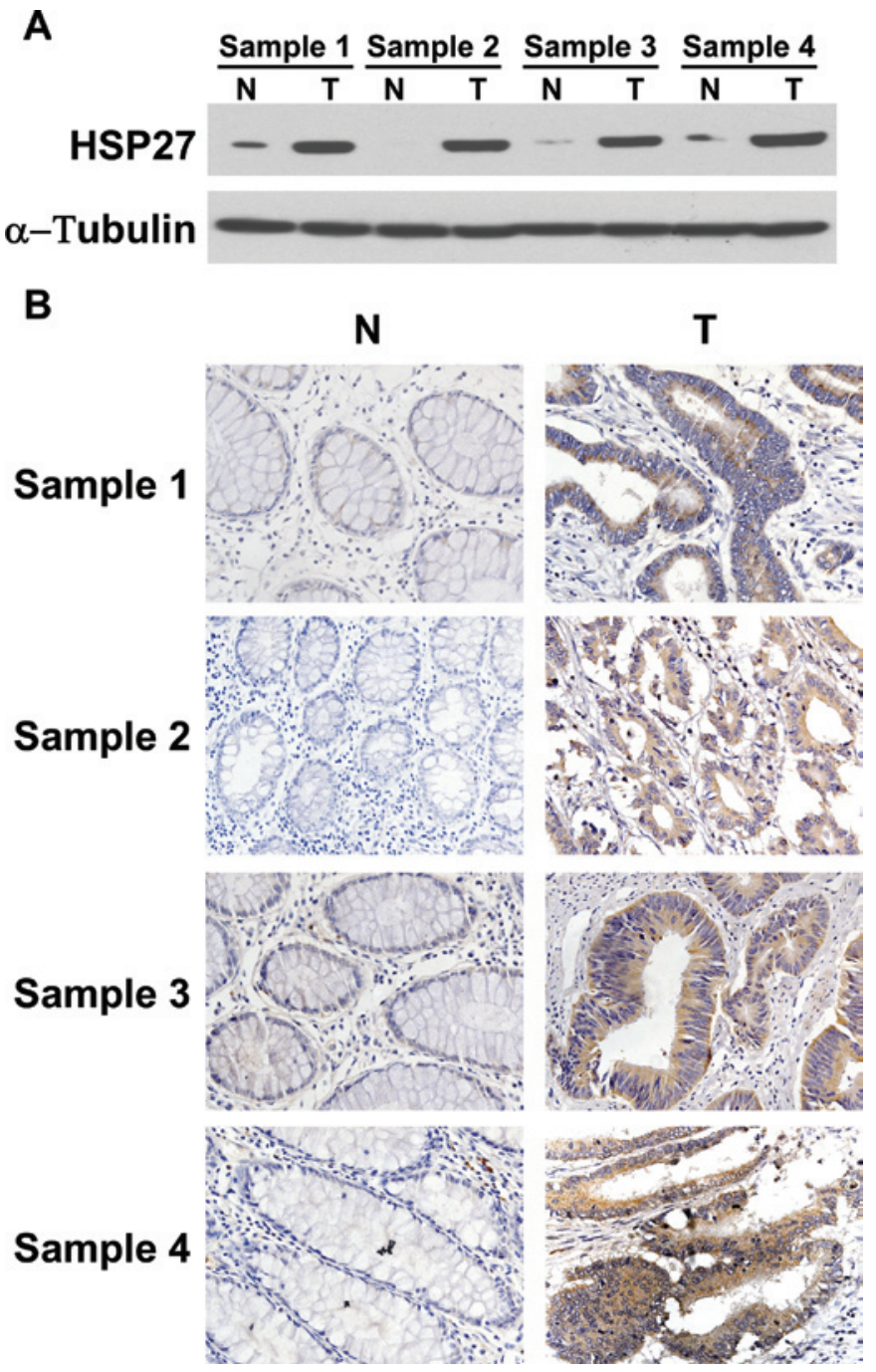

Figure 1. Analysis of HSP27 protein expression in CRC tissues (T) and adjacent non-cancerous mucosa $(\mathrm{N})$ from the same patient using Western blot (A) and immunohistochemical (B) analyses.

Expression of HSP27 in archival CRC specimens. To further elucidate whether the HSP27 protein expression is upregulated and is associated with progression of CRC, we examined 182 paraffin-embedded archived CRC specimens by performing immunohistochemistry with an antibody against human HSP27. Thirty-seven (20.3\%) tumor samples were immunonegative for HSP27, whereas 145 (79.7\%) cases showed detectable immunoreactivity (weak, intermediate, strong). Ninety-six (52.7\%) cases with negative and weak staining were identified as exhibiting low HSP27 expression, while 86 (47.3\%) cases with intermediate and strong staining exhibited high HSP27 expression (Fig. 2). The immunoreactivity of HSP27 was present mainly in the cytoplasm of the tumor cells.

Statistical analyses were carried out to investigate the correlation between HSP27 expression and the clinicopathological features of CRC. As shown in Table II, no significant correlation was found between the expression level of HSP27 and gender $(\mathrm{P}=0.677)$, age $(\mathrm{P}=0.194)$, tumor differentiation $(\mathrm{P}=0.220)$, tumor site $(\mathrm{P}=0.875)$ or tumor size $(\mathrm{P}=0.170)$. Of note, the expression of HSP27 was strongly correlated with the TNM stage of patients with CRC $(\mathrm{P}=0.003)$. The correlation
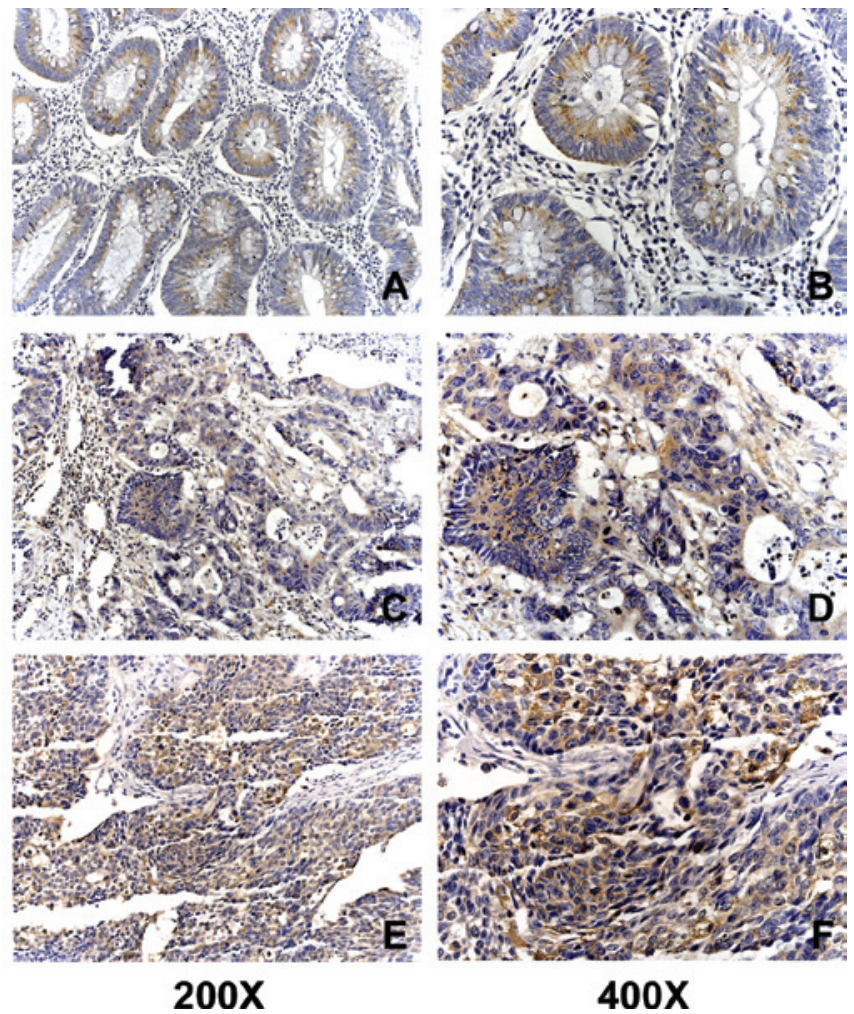

Figure 2. Immunohistochemical (IHC) staining of HSP27 protein in CRC tissue sections. Representative images from IHC staining of 182 archived samples of CRC. (A and B) Well-differentiated, (C and D) moderately differentiated, (E and F) poorly differentiated.

Table II. Comparison of low versus high HSP27 expression in $\mathrm{CRC}$ tissues as a function of clinicohistological factors.

\begin{tabular}{lccc}
\hline & \multicolumn{2}{c}{ HSP27 expression } & \\
\cline { 2 - 3 } Characteristics & Low (n) & High (n) & P-value \\
\hline Gender & & & \\
$\quad$ Male & 54 & 51 & 0.677 \\
Female & 42 & 35 & \\
Age & & & \\
$\leq 61$ & 41 & 45 & 0.194 \\
$>61$ & 55 & 41 & \\
TNM stage & & & \\
0, I and II & 70 & 47 & 0.003 \\
III and IV & 18 & 33 & \\
Tumor differentiation & & & \\
Well & 45 & 48 & 0.220 \\
Poor & 39 & 28 & \\
Tumor site & & & \\
Colon & 28 & 26 & 0.875 \\
Rectum & 68 & 60 & \\
Tumor size & & & \\
$\leq 5 \mathrm{~cm}$ & 31 & 37 & 0.170 \\
$>5 \mathrm{~cm}$ & 33 & 24 & \\
\hline
\end{tabular}




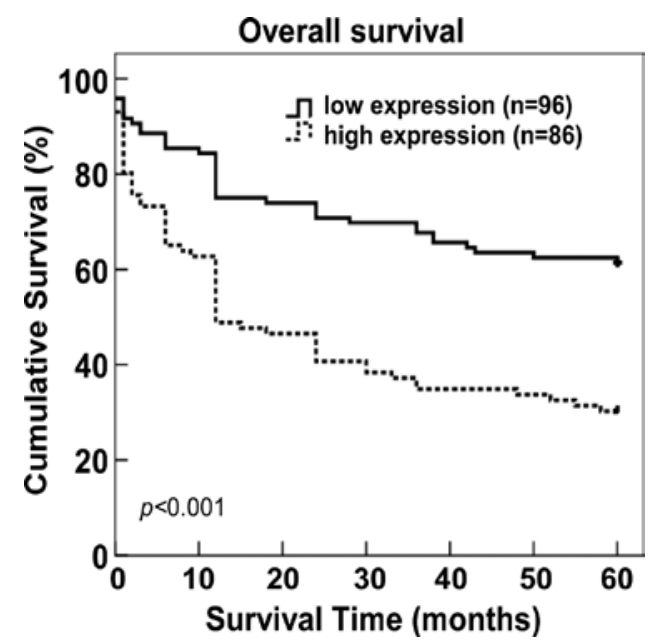

Figure 3. Comparison of survival rates in patients with high and low HSP27expressing tumors using Kaplan-Meier curves with univariate analyses. The cumulative 5-year survival rate $(0.63,95 \% \mathrm{CI}, 0.532-0.728)$ of patients with low HSP27 expression was significantly higher than that of patients with high HSP27 expression (0.30, 95\% CI, 0.172-0.398). P-values were calculated using the log-rank test.

between HSP27 expression and clinicopathological parameters was further confirmed using Spearman correlation analysis. The results showed a Spearman correlation of HSP27 to TNM stage $(\mathrm{P}=0.002)$ (Table II). Taken together, the results indicate that the expression of HSP27 is upregulated and likely associated with disease progression in CRC.

Survival analysis. Kaplan-Meier analysis and the log-rank test were used to analyze the correlation between HSP27 expression and patient survival. As shown in Fig. 3, the low HSP27
Table III. Spearman correlation analysis between HSP27 and clinicohistological parameters.

\begin{tabular}{lcc}
\hline & \multicolumn{2}{c}{ HSP27 expression } \\
\cline { 2 - 3 } Characteristics & Spearman correlation & P-value \\
\hline Gender & -0.002 & 0.981 \\
Age & -0.210 & 0.779 \\
TNM stage & 0.206 & 0.002 \\
Tumor differentiation & 0.059 & 0.456 \\
Tumor site & 0.067 & 0.425 \\
Tumor size & 0.123 & 0.173 \\
\hline
\end{tabular}

expression group had better survival in comparison with the high HSP27 expression group. The log-rank test demonstrated that the survival time between the low and high HSP27 expression groups was significantly different $(\mathrm{P}=0.000)$. The mean survival time of the low and high HSP27 expression groups was 43.22 [95\% confidence interval (CI), 38.47-47.97] and 26.97 months (95\% CI, 21.69-32.23), respectively. Moreover, the cumulative 5-year survival rate $(0.63,95 \% \mathrm{CI}, 0.532$ 0.728 ) of patients with low HSP27 expression was significantly higher than that of patients with high HSP27 expression ( 0.30 , 95\% CI, 0.172-0.398) (Fig. 3). In addition, multivariate Cox regression analysis revealed that HSP27 expression was an independent prognostic factor for patients with $\mathrm{CRC}(\mathrm{P}=0.001)$ (Table IV). Overall, these data suggest that the overexpression of HSP27 protein in CRC has a strong correlation with the prognosis of patients.

Table IV. Univariate and multivariate Cox-regression analysis of various prognostic parameters in patients with CRC.

\begin{tabular}{|c|c|c|c|c|c|}
\hline \multirow[b]{2}{*}{ Characteristics } & \multicolumn{2}{|r|}{ Univariate analysis } & \multicolumn{3}{|c|}{ Multivariate analysis } \\
\hline & P-value & Regression coefficient (SE) & P-value & Relative risk & 95\% Confidence interval \\
\hline \multicolumn{6}{|l|}{ Gender } \\
\hline Male vs. Female & 0.365 & $1.350(0.228)$ & - & - & - \\
\hline \multicolumn{6}{|l|}{ Age } \\
\hline$\leq 61$ vs. $>61$ & 0.189 & $1.229(0.228)$ & - & - & - \\
\hline \multicolumn{6}{|l|}{ TNM stage } \\
\hline 0, I and II vs. III and IV & 0.000 & $2.596(0.231)$ & 0.000 & 2.345 & $1.481-3.713$ \\
\hline \multicolumn{6}{|l|}{ Tumor differentiation } \\
\hline Well vs. Poor & 0.411 & $1.206(0.227)$ & - & - & - \\
\hline \multicolumn{6}{|l|}{ Tumor site } \\
\hline Colon vs. Rectum & 0.159 & $1.409(0.243)$ & - & - & - \\
\hline \multicolumn{6}{|l|}{ HSP27 expression } \\
\hline Low vs. High & 0.000 & $2.502(0.235)$ & 0.001 & 2.212 & $1.387-3.529$ \\
\hline \multicolumn{6}{|l|}{ Chemotherapy after surgery } \\
\hline Yes vs. No & 0.030 & $0.593(0.240)$ & 0.026 & 0.585 & $0.365-0.938$ \\
\hline
\end{tabular}




\section{Discussion}

Our study provides evidence that HSP27 is highly expressed in CRC patients and is strongly correlated with histological grade and poor outcome in these patients. We also demonstrated that patients with higher expression of HSP27 had a short overall survival time, whereas patients with lower HSP27 expression had a more favorable survival. Thus, upregulation of HSP27 might represent an independent prognostic factor for patients with CRC.

HSP27, a subfamily of small HSPs, has been found to be constitutively upregulated in a variety of malignancies. Moreover, overexpression of HSP27 is associated with multiple aspects of carcinogenesis, including the suppression of apoptosis, increased cytoprotection and multidrug resistance (17). Overexpressed HSP27 is capable of inhibiting apoptotic cell death by directly interacting with different apoptotic proteins at key regulatory points in the control of apoptosis. HSP27 may prevent the formation of the apoptosome by either directly sequestering cytochrome $\mathrm{c}$ when it is released from the mitochondria or by preventing the release of mitochondrial cytochrome $\mathrm{c}$, thus leading to the inactivation of caspases $(21,22)$. The finding that HSP27 interferes with caspase activation upstream of the mitochondria may be attributed to its ability to stabilize and accelerate the recovery of actin microfilaments $(23,24)$. HSP27 has been shown to inhibit apoptosis by increasing the antioxidant defense of cells (25). Moreover, HSP27 also inhibits apoptosis by regulating various upstream signaling pathways, such as those involving protein kinase Akt (26), the Fas-mediated caspase-independent

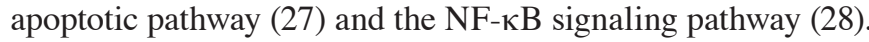
These antiapoptotic effects underscore the potential role of HSP27 in cancer resistance to chemotherapy and radiotherapy, which has been extensively studied. Chauhan and colleagues demonstrated that HSP27 confers bortezomib (PS-341) resistance to DHL4 lymphoma cells (29). It was also shown that HSP27 overexpression plays an important role in resistance to doxorubicin by altering the expression of topoisomerase II in breast cancer cells $(30,31)$. Reduction of HSP27 expression by small interfering RNA (siRNA) attenuated its role in resisting oxidant stress, thereby increasing the chemosensitivity of HO8910 human ovarian cancer to paclitaxel (32). Furthermore, studies have shown the effect of HSP27 in inhibiting radiationinduced apoptosis in several types of cancers, suggesting that inhibition of HSP27 expression acts as a radiation sensitizer in radioresistant cancers (33-35). In addition, deregulated HSP27 expression has been found to contribute to cell invasion and metastasis (36). Collectively, these findings suggest that HSP27 may play an important role in cancer development and progression and response to therapy.

Many studies have explored the role of HSP27 in CRC development and progression. Expression of HSP27 in CRC cells enhances their apoptotic resistance in vitro and significantly increases their tumorigenicity in vivo (37). There are also data suggesting that HSP27 is involved in irinotecan and 5 -fluorouracil resistance in CRC $(38,39)$. Very recently, Liu and coworkers (19) observed that HSP27 is differentially expressed in CRC tissues and neighboring normal mucosa by using highly sensitive two-dimensional gel electrophoresis coupled with matrix-assisted laser desorption/ionization time of flight mass spectrometry. Nevertheless, thus far the prognostic significance of HSP27 for CRC is not clear. This prompted us to ascertain whether the expression of HSP27 is clinically associated with the progression of CRC.

In the present study, we showed that upregulation of HSP27 protein is a common event in human CRC tissues. One hundred and forty-five of the 182 (79.7\%) paraffin-embedded CRC specimens displayed positive staining of HSP27 in the tumor cells. Further statistical analysis of the relationship between HSP27 expression and clinicopathological parameters of the CRC patients demonstrated a significant correlation between HSP27 expression and the TNM staging of $\mathrm{CRC}$, revealing elevated HSP27 expression in higher grades of the disease. These data support the hypothesis that HSP27 is involved in the progression of CRC, and that it represents a biomarker that identifies subsets of CRC patients with poorer clinical outcome.

We next investigated the impact of observed HSP27 overexpression on patient survival. Intriguingly, patients with high expression of HSP27 had worse survival (cumulative 5-year survival rate of $30 \%$ ) than patients with low HSP27 expression (cumulative 5-year survival rate of 63\%), implying the possibility that HSP27 may be used as a predictive marker for patient prognosis and survival. In a more detailed survival study, we further confirmed by multivariate Cox analysis that HSP27 overexpression appears to function as an independent prognostic factor of overall survival after adjustment for TNM stage and the use of adjuvant chemotherapy.

According to our and other studies, HSP27 is constitutively highly expressed in many tumors without any stress, despite the fact that it is ubiquitously expressed at low levels in normal cells and accumulates significantly under treatments with a wide variety of stresses. However, up until now the mechanisms underlying HSP27 overexpression in cancer remain poorly understood. Studies suggest that upregulated HSP27 expression may be due to the physiopathological features of the tumor microenvironment, such as low glucose, low $\mathrm{pH}$ and low oxygen (40). Further studies that focus on the mechanism of HSP27 upregulation in CRC will enhance our understanding of the pathogenesis of CRC.

We investigated the expression of HSP27 in human CRC specimens. The results reveal for the first time that elevated HSP27 expression correlates with poor prognosis in patients with CRC. The analysis of HSP27 expression may be useful for identifying patient subgroups at high risk for poor clinical outcome, thereby helping to assess therapeutic strategies for CRC patients.

In conclusion, the relationship between HSP27 expression and the prognosis of patients with CRC has not been investigated to date. Our results suggest that deregulated HSP27 expression is a frequent event during the disease progression of CRC. The expression of HSP27 is associated with poor overall survival and may represent an independent prognostic factor in patients with CRC. More aggressive therapy should be considered in CRC patients with high expression of this marker.

\section{Acknowledgements}

This study was supported by the Medical Research Fund of Guangdong Province (no. A2008754) and the Science and Technology Project Fund of Huizhou (no. 2010Y063). 


\section{References}

1. Moghaddam AA, Woodward M and Huxley R: Obesity and risk of colorectal cancer: a meta-analysis of 31 studies with 70,000 events. Cancer Epidemiol Biomarkers Prev 16: 2533-2547, 2007.

2. Inomata M, Yasuda K, Shiraishi N and Kitano S: Clinical evidences of laparoscopic versus open surgery for colorectal cancer. Jpn J Clin Oncol 39: 471-477, 2009.

3. Hundt S, Haug U and Brenner H: Blood markers for early detection of colorectal cancer: a systematic review. Cancer Epidemiol Biomarkers Prev 16: 1935-1953, 2007.

4. Brundel BJ, Ke L, Dijkhuis AJ, Qi XY, Shiroshita-Takeshita A, Nattel S, Henning RH and Kampinga HH: Heat shock proteins as molecular targets for intervention in atrial fibrillation. Cardiovasc Res 78: 422-428, 2008.

5. Pockley AG: Heat shock proteins, inflammation, and cardiovascular disease. Circulation 105: 1012-1017, 2002.

6. Nollen EA and Morimoto RI: Chaperoning signaling pathways: molecular chaperones as stress-sensing 'heat shock' proteins. J Cell Sci 115: 2809-2816, 2002.

7. Westerheide SD and Morimoto RI: Heat shock response modulators as therapeutic tools for diseases of protein conformation. J Biol Chem 280: 33097-33100, 2005.

8. Matsui Y, Hadaschik BA, Fazli L, Andersen RJ, Gleave ME and So AI: Intravesical combination treatment with antisense oligonucleotides targeting heat shock protein-27 and HTI-286 as a novel strategy for high-grade bladder cancer. Mol Cancer Ther 8: 2402-2411, 2009.

9. Tetu B, Brisson J, Landry J and Huot J: Prognostic significance of heat-shock protein-27 in node-positive breast carcinoma: an immunohistochemical study. Breast Cancer Res Treat 36: 93-97, 1995.

10. Geisler JP, Tammela JE, Manahan KJ, Geisler HE, Miller GA, Zhou Z and Wiemann MC: HSP27 in patients with ovarian carcinoma: still an independent prognostic indicator at 60 months follow-up. Eur J Gynaecol Oncol 25: 165-168, 2004.

11. Giaginis C, Daskalopoulou SS, Vgenopoulou S, Sfiniadakis I, Kouraklis G and Theocharis SE: Heat shock protein-27, -60 and -90 expression in gastric cancer: association with clinicopathological variables and patient survival. BMC Gastroenterol 9: 14, 2009.

12. Foster CS, Dodson AR, Ambroisine L, Fisher G, Moller H, Clark J, Attard G, De-Bono J, Scardino P, Reuter VE, Cooper CS, Berney DM and Cuzick J: Hsp-27 expression at diagnosis predicts poor clinical outcome in prostate cancer independent of ETS-gene rearrangement. Br J Cancer 101: 1137-1144, 2009.

13. Ioachin E: Immunohistochemical tumour markers in endometrial carcinoma. Eur J Gynaecol Oncol 26: 363-371, 2005.

14. Joo M, Chi JG and Lee H: Expressions of HSP70 and HSP27 in hepatocellular carcinoma. J Korean Med Sci 20: 829-834, 2005.

15. Storm FK, Mahvi DM and Gilchrist KW: Hsp-27 has no diagnostic or prognostic significance in prostate or bladder cancers. Urology 42: 379-382, 1993.

16. Tavernier E, Duval A, Cornillon J, Flandrin P, Guyotat D and Campos L: Prognostic value of CXCR4, adhesion molecules and heat shock proteins (HSP) in acute myelogenous leukemia. Blood (ASH Annual Meeting Abstracts) 110: 2848, 2007.

17. Ciocca DR and Calderwood SK: Heat shock proteins in cancer: diagnostic, prognostic, predictive, and treatment implications. Cell Stress Chaperones 10: 86-103, 2005.

18. Garrido C, Brunet M, Didelot C, Zermati Y, Schmitt E and Kroemer G: Heat shock proteins 27 and 70: anti-apoptotic proteins with tumorigenic properties. Cell Cycle 5: 2592-2601, 2006.

19. Liu W, Ma Y, Huang L, Peng J, Zhang P, Zhang H, Chen J and Qin H: Identification of HSP27 as a potential tumor marker for colorectal cancer by the two-dimensional polyacrylamide gel electrophoresis. Mol Biol Rep (In press).

20. Schimanski CC, Schwald S, Simiantonaki N, Jayasinghe C, Gönner U, Wilsberg V, Junginger T, Berger MR, Galle PR and Moehler M: Effect of chemokine receptors CXCR4 and CCR7 on the metastatic behavior of human colorectal cancer. Clin Cancer Res 11: 1743-1750, 2005

21. Bruey JM, Ducasse C, Bonniaud P, Ravagnan L, Susin SA, DiazLatoud C, Gurbuxani S, Arrigo AP, Kroemer G, Solary E and Garrido C: Hsp27 negatively regulates cell death by interacting with cytochrome c. Nat Cell Biol 2: 645-652, 2000.

22. Garrido C, Bruey JM, Fromentin A, Hammann A, Arrigo AP and Solary E: HSP27 inhibits cytochrome c-dependent activation of procaspase-9. FASEB J 13: 2061-2070, 1999.
23. Lavoie JN, Gingras-Breton G, Tanguay RM and Landry J: Induction of Chinese hamster HSP27 gene expression in mouse cells confers resistance to heat shock. HSP27 stabilization of the microfilament organization. J Biol Chem 268: 3420-3429, 1993.

24. Guay J, Lambert H, Gingras-Breton G, Lavoie JN, Huot J and Landry J: Regulation of actin filament dynamics by p38 map kinase-mediated phosphorylation of heat shock protein 27. J Cell Sci 110: 357-368, 1997.

25. Wyttenbach A, Sauvageot O, Carmichael J, Diaz-Latoud C, Arrigo AP and Rubinsztein DC: Heat shock protein 27 prevents cellular polyglutamine toxicity and suppresses the increase of reactive oxygen species caused by huntingtin. Hum Mol Genet 11: 1137-1151, 2002

26. Konishi H, Matsuzaki H, Tanaka M, Takemura Y, Kuroda S, Ono Y and Kikkawa U: Activation of protein kinase B (Akt/ RAC-protein kinase) by cellular stress and its association with heat shock protein Hsp27. FEBS Lett 410: 493-498, 1997.

27. Charette SJ and Landry J: The interaction of Hsp27 with Daxx identifies a potential regulatory role of Hsp27 in Fas-induced apoptosis. Ann NY Acad Sci 926: 126-131, 2000.

28. Guo K, Kang NX, Li Y, Sun L, Gan L, Cui FJ, Gao MD and Liu KY: Regulation of HSP27 on NF-kappaB pathway activation may be involved in metastatic hepatocellular carcinoma cell apoptosis. BMC Cancer 9: 100, 2009.

29. Chauhan D, Li G, Shringarpure R, Podar K, Ohtake Y, Hideshima T and Anderson KC: Blockade of Hsp27 overcomes bortezomib/proteasome inhibitor PS-341 resistance in lymphoma cells. Cancer Res 63: 6174-6177, 2003.

30. Oesterreich S, Weng CN, Qiu M, Hilsenbeck SG, Osborne CK and Fuqua SA: The small heat shock protein hsp27 is correlated with growth and drug resistance in human breast cancer cell lines. Cancer Res 53: 4443-4448, 1993.

31. Hansen RK, Parra I, Lemieux P, Oesterreich S, Hilsenbeck SG and Fuqua SA: Hsp27 overexpression inhibits doxorubicininduced apoptosis in human breast cancer cells. Breast Cancer Res Treat 56: 187-196, 1999.

32. Song TF, Zhang ZF, Liu L, Yang T, Jiang J and Li PL: Small interfering RNA-mediated silencing of heat shock protein 27 (HSP27) increases chemosensitivity to paclitaxel by increasing production of reactive oxygen species in human ovarian cancer cells (HO8910). J Int Med Res 37: 1375-1388, 2009.

33. Teimourian S, Jalal R, Sohrabpour M and Goliaei B: Downregulation of Hsp27 radiosensitizes human prostate cancer cells. Int J Urol 13: 221-1225, 2006.

34. Aloy MT, Hadchity E, Bionda C, Diaz-Latoud C, Claude L, Rousson R, Arrigo AP and Rodriguez-Lafrasse C: Protective role of $\mathrm{Hsp} 27$ protein against gamma radiation-induced apoptosis and radiosensitization effects of Hsp27 gene silencing in different human tumor cells. Int J Radiat Oncol Biol Phys 70: 543-553, 2008

35. Hadchity E, Aloy MT, Paulin C, Armandy E, Watkin E, Rousson R, Gleave M, Chapet $\mathrm{O}$ and Rodriguez-Lafrasse C: Heat shock protein 27 as a new therapeutic target for radiation sensitization of head and neck squamous cell carcinoma. Mol Ther 17: 1387-1394, 2009

36. Nakajima M, Kuwano H, Miyazaki T, Masuda N and Kato H: Significant correlation between expression of heat shock proteins 27,70 and lymphocyte infiltration in esophageal squamous cell carcinoma. Cancer Lett 178: 99-106, 2002.

37. Garrido C, Fromentin A, Bonnotte B, Favre N, Moutet M, Arrigo AP, Mehlen P and Solary E: Heat shock protein 27 enhances the tumorigenicity of immunogenic rat colon carcinoma cell clones. Cancer Res 58: 5495-5499, 1998.

38. Choi DH, Ha JS, Lee WH, Song JK, Kim GY, Park JH, Cha HJ, Lee BJ and Park JW: Heat shock protein 27 is associated with irinotecan resistance in human colorectal cancer cells. FEBS Lett 581: 1649-1656, 2007.

39. Tsuruta M, Nishibori H, Hasegawa H, Ishii Y, Endo T, Kubota T, Kitajima $M$ and Kitagawa Y: Heat shock protein 27, a novel regulator of 5-fluorouracil resistance in colon cancer. Oncol Rep 20: $1165-1172,2008$

40. Kawanishi K, Shiozaki H, Doki Y, Sakita I, Inoue M, Yano M, Tsujinaka T, Shamma A and Monden M: Prognostic significance of heat shock proteins 27 and 70 in patients with squamous cell carcinoma of the esophagus. Cancer 85: 1649-1657, 1999. 